\title{
Origin types of the long thoracic nerve
}

\author{
Fatih Yazar · Ayhan Comert
}

Received: 18 March 2009 / Accepted: 2 April 2009 / Published online: 5 May 2009

(C) Springer-Verlag 2009

\section{Dear Editor,}

We read with interest the article entitled "Observation and measurements of long thoracic nerve: a cadaver study and clinical consideration" by Wang et al. [2]. This is an important study regarding contributions of LTN and knowledge about their origins. There are some contradictions and confusing points in this article. It was to point out that "Different derivations of LTN were observed, and C4-7, C5-7, C5 and $\mathrm{C} 7, \mathrm{C} 5-7, \mathrm{C} 5-8, \mathrm{C} 6$ and $\mathrm{C} 7$, and branch from $\mathrm{C} 6$ was the most important components of LTN" [2] in the abstract section. But at the end of the result section "Branch from C6 was observed in all cadavers and thicker than those from C5 and C7" [2]. If this sentence was correct, derivation of $\mathrm{C} 5$ and $\mathrm{C} 7$ was wrong. Due to this, derivation could not involve C6. On the other hand at the beginning of the result section, six types of LTN were mentioned, but there are five types of the LTN in the Table 1. In addition, it was also stressed that "No absence of branch from C6 had been reported and it was certified by measurement data that $\mathrm{C} 6$ was more important than others in forming LTN in the present study" [2]. This also shows that C6 always contribute to LTN. Contributions from the C6 nerve root are common and constant, while the contributions from $\mathrm{C} 5$ and $\mathrm{C} 7$ cervical roots are more variable [1].

F. Yazar $(\bowtie)$

Department of Anatomy, Faculty of Medicine, Gulhane Military Medical Academy,

Etlik, Ankara, Turkey

e-mail: fyazar@gata.edu.tr

\section{A. Comert}

Department of Anatomy, Faculty of Medicine, Ankara University, Sihhiye, Ankara, Turkey
We recommend that "six types of LTN" stated in study of Wang et al. [2] is wrong and it should be changed with five types of LTN and type of "C5 and C7" should be omitted from abstract and from result sections.

\section{References}

1. Berry M, Bannister LH, Standring SM (1995) Nervous system. In: Williams PL, Bannister LH, Berry MM, Collins P, Dyson M, Dussek JE, Ferguson MWJ (eds) Gray's anatomy, 38th edn. Churchill Livingstone, Philadelphia, pp 1267-1268

2. Wang JF, Dang RS, Wang D, Zhang ZY, Liu Z, Huang HL, Wu AQ, Zhang CS, Chen EY (2008) Observation and measurements of long thoracic nerve: a cadaver study and clinical consideration. Surg Radiol Anat 30:569-573 